\title{
Downregulation of miR-505 promotes cell proliferation, migration and invasion, and predicts poor prognosis in breast cancer
}

\author{
JIAN WANG ${ }^{*}$, HAIBO LIU* and MINGHONG LI \\ Department of Laboratory Medicine, Yidu Central Hospital of Weifang, Weifang, Shandong 262500, P.R. China
}

Received July 26, 2018; Accepted April 15, 2019

DOI: $10.3892 / \mathrm{ol} .2019 .10334$

\begin{abstract}
RNAs are involved in the tumor progression of various cancer types. The present study aimed to determine the prognostic significance of microRNA-505 (miR-505) in patients with breast cancer and investigate the functional role of miR-505 in BCa progression. The expression of miR-505 was estimated using reverse transcription-quantitative polymerase chain reaction. Kaplan-Meier survival curves and Cox regression analysis were used to evaluate the prognostic value of miR-505 in patients with $\mathrm{BCa}$. Cell experiments were performed to assess the biological function of miR-505 during $\mathrm{BCa}$ progression. A significant downregulated expression level of miR-505 was observed in BCa tissues and cells compared with the corresponding controls $(\mathrm{P}<0.001)$. The expression of miR-505 was significantly associated with distant metastasis status $(\mathrm{P}=0.013)$ and Tumor-Node-Metastasis staging $(\mathrm{P}=0.002)$. Furthermore, the overall survival time was significantly shorter for patients with low miR-505 expression compared with those with high miR-505 expression $(\mathrm{P}<0.001)$. In addition, miR-505 was identified as an independent prognostic factor for $\mathrm{BCa}$. The results of cell experiments revealed that an overexpression of miR-505 could significantly inhibit $\mathrm{BCa}$ cell proliferation, migration and invasion, whereas a downregulation of miR-505 significantly enhanced BCa cell proliferation, migration and invasion $(\mathrm{P}<0.05)$. In summary, all data indicated that a low miR-505 expression level is associated with a poor prognosis for patients with $\mathrm{BCa}$ and promotes tumor cell proliferation, migration and invasion. Therefore, the aberrant expression of miR-505 may serve as a therapeutic target for $\mathrm{BCa}$.
\end{abstract}

Correspondence to: Dr Jian Wang, Department of Laboratory Medicine, Yidu Central Hospital of Weifang, 4138 South Linglongshan Road, Weifang, Shandong 262500, P.R. China

E-mail: zou8402pidao@163.com

${ }^{*}$ Contributed equally

Key words: microRNA-505, prognosis, proliferation, migration, invasion, breast cancer

\section{Introduction}

Breast cancer (BCa) is the most common type of malignancy in females worldwide and is responsible for cancer-associated mortality (1). $\mathrm{BCa}$ is a highly heterogeneous and malignant disease that can be classified into a number of subtypes based on the status of molecular markers, including the expression of estrogen receptor (ER), progesterone receptor (PR) and human epidermal growth factor receptor 2 (HER2) (2). $\mathrm{BCa}$ is typically considered a complex malignancy, which is predominantly due to its varied etiology, including certain environmental factors and genetic changes (3). Therefore, the majority of $\mathrm{BC}$ cases exhibit a range of different pathological entities and clinical manifestations, which can lead to misdiagnosis or delayed diagnosis (4). Despite advancements in diverse therapeutic strategies, including surgical resection, chemotherapy and radiotherapy, the overall survival rate of patients with BCa remains poor (5). Additionally, the current therapeutic strategies have been reported to possess certain adverse side effects, including poor specificity or a limited response to chemotherapy (6). Therefore, the identification of functional molecules that serve crucial roles during $\mathrm{BCa}$ initiation and development is urgently required to improve understanding of the underlying mechanisms of $\mathrm{BCa}$ and promote the development of novel treatment strategies.

MicroRNAs (miRNAs) are a group of short, non-coding RNA molecules that consist of $\sim 23$ nucleotides and serve important regulatory roles in gene expression at the post-transcriptional level (7). miRNAs can bind to the 3'-untranslated region of a target mRNA, which leads to suppression of the target mRNA or promotion of mRNA degradation (8). miRNAs have been reported to be involved in various biological processes, including cell proliferation, differentiation, invasion, migration and apoptosis, in normal and tumor cells (9-12). In recent decades, the functional roles of miRNAs in tumor progression have been identified in different types of human cancer, which has increased attention regarding the aberrant expression of miRNAs in tumor samples (13-15). miRNAs may potentially be used in cancer-targeted therapy and typically exhibit a high diagnostic and prognostic significance in patients with cancer $(16,17)$. Therefore, there is a requirement to identify additional functional miRNAs in $\mathrm{BCa}$ progression, as they may be beneficial in BCa treatment. miRNA-505 (miR-505) has been reported to act as a tumor suppressor and inhibit tumor progression in certain types of human cancer, including 
osteosarcoma (18), cervical cancer (19), hepatoma (20) and endometrial cancer (21). Matamala et al (22) revealed that miR-505 is downregulated in breast cancer tissues. However, the clinical and functional role of miR-505 in breast cancer remains elusive.

The present study investigated the expression levels of miR-505 in BCa tissues and cells. In addition, the prognostic significance of miR-505 was evaluated for patients with BCa. Finally, the effect of miR-505 on the behaviour of BCa cells was evaluated.

\section{Materials and methods}

Patients and tissue collection. A total of 128 patients with a mean age of $58.3 \pm 12.9$ years (range, 35-80 years), who were pathologically diagnosed with $\mathrm{BCa}$ and underwent surgical resection between July 2008 and June 2012 at Yidu Central Hospital of Weifang (Weifang, China), were included in the present study. None of the patients had previously received any antitumor therapy and the electronic medical records of all patients were complete. The BCa tissue samples and adjacent normal tissue samples (at least $5 \mathrm{~cm}$ from the edge of the tumor tissue) were collected from the patients during surgery and immediately frozen with liquid nitrogen for future use. The demographic and clinicopathologic data are summarized in Table I. The Tumor-Node-Metastasis (TNM) stage of the patients was determined according to the criteria published by the American Joint Committee on Cancer classification (23). Distant metastasis indicated that the tumor had spread to the whole tissue or other organs, including the lungs, brain, bone and liver. Each patient provided written informed consent and their personal information was anonymized. The experimental procedures of the present study were approved by the Ethics Committee of Yidu Central Hospital of Weifang (Weifang, China). The patients were enrolled in a 5-year follow-up survey following surgery and the survival information was obatined by telephone communication.

Cell culture and transfection. The four BCa cell lines MCF-7, BT474, T47D and MDA-MB-231, and the normal mammary epithelial cell line MCF-10A were obtained from American Type Culture Collection (Manassas, MA, USA). The cells were cultured in Dulbecco's modified Eagle's medium (DMEM; Gibco; Thermo Fisher Scientific, Inc., Waltham, MA, USA) supplemented with $10 \%$ fetal bovine serum (FBS; Gibco; Thermo Fisher Scientific, Inc.) and maintained in a $5 \% \mathrm{CO}_{2}$ atmosphere at $37^{\circ} \mathrm{C}$.

Two BCa cell lines MCF-7 and MDA-MB-231, which had low expression of miR-505, were seeded in 24-well plates and cultured for $24 \mathrm{~h}$ at $37^{\circ} \mathrm{C}$. Following incubation, the cells were transfected with $20 \mathrm{nM}$ miR-505 mimic, miR-505 inhibitor, mimic negative control (NC) or inhibitor $\mathrm{NC}$ using Lipofectamine ${ }^{\circledR} 2000$ (Invitrogen; Thermo Fisher Scientific, Inc.), according to the manufacturer's protocol. The vectors used in transfection were obtained from Shanghai GenePharma Co., Ltd. (Shanghai, China). The MiR sequences were as follows: miR-505 mimic, 5'-GGGAGCCAGGAAGUAUUGAUGU-3'; miR-505 inhibitor, 5'-ACAUCAAUACUUCCUGGCUCCC-3'; mimic NC, 5'-UUCUCCGAACGUGUCACGUTT-3'; inhibitor NC, 5'-CAGUACUUUUGUGUAGUACAA-3'. Cells were used for subsequent experimentation $48 \mathrm{~h}$ following transfection.
RNA extraction and reverse transcription-quantitative polymerase chain reaction ( $R T-q P C R)$. Total RNA was extracted from the tissue samples and the five cell lines using TRIzol ${ }^{\circledR}$ reagent (Invitrogen; Thermo Fisher Scientific, Inc.). A NanoDrop 2000 (Thermo Fisher Scientific, Inc.) was used to evaluate the concentration and quality of the RNA. Single-stranded complementary DNA was synthesized from $1 \mu \mathrm{g}$ RNA using a PrimeScript RT reagent kit (Takara Bio, Inc., Otsu, Japan) and stored at $-20^{\circ} \mathrm{C}$.

The expression levels of miR-505 were examined using qPCR, which was performed with a SYBR-Green I Master mix kit (Invitrogen; Thermo Fisher Scientific, Inc.) using a 7300 Real-Time PCR system (Applied Biosystems; Thermo Fisher Scientific, Inc.). The following thermocycling conditions were used for the qPCR: initial denaturation at $95^{\circ} \mathrm{C}$ for $10 \mathrm{~min} ; 40$ cycles of $95^{\circ} \mathrm{C}$ for $30 \mathrm{sec}, 58^{\circ} \mathrm{C}$ for $30 \mathrm{sec}$, and $72^{\circ} \mathrm{C}$ for $20 \mathrm{sec}$. U6 was used as an internal control. The primers for qPCR were as follows: miR-505 forward, 5'-CTACGTGGG TCACCCCCTC-3' and reverse, 5'-CCAAAGGAGACCTCG TAG-3'; and U6 forward, 3'-GCTTCGGCAGCACATATA CTAAAAT-5' and reverse, 3'-CGCTTCACGAATTTGCGT GTCAT-5'. The expression data were calculated using the $2^{-\Delta \Delta \mathrm{Cq}}$ method (24) and normalized to the U6 expression level.

\section{Cell proliferation analysis. The MCF-7 and MDA-MB-231} cells were transfected with miR-505 mimic, miR-505 inhibitor or NCs as aforementioned. Following transfection, the stably transfected cells were seeded in 96-well plates at a cell concentration of $4 \times 10^{5}$ cells/well. Following incubation for 0, 24, 48 or $72 \mathrm{~h}, 20 \mu 1 \mathrm{MTT}(5 \mathrm{~g} / \mathrm{l}$; Ameresco) was added to each well and the cells were then further cultured for $4 \mathrm{~h}$ at $37^{\circ} \mathrm{C}$. The medium was then removed and $150 \mu \mathrm{l}$ dimethyl sulfoxide was added to the wells to dissolve the formazan. Cell proliferation was evaluated by examining the absorbance at $490 \mathrm{~nm}$ using a microplate reader.

Cell migration and invasion analysis. The BCa cell migration and invasion abilities were assessed using a Transwell system (Corning, Inc., Corning, NY, USA) with $8-\mu \mathrm{m}$ pore size membranes. Membranes pre-coated with Matrigel (Corning, Inc.) were used for the invasion analysis. The MCF-7 and MDA-MB-231 cells were harvested at $48 \mathrm{~h}$ post-transfection and seeded in the upper chambers of the Transwell system at a concentration of $4 \times 10^{5}$ cells/well. Serum-free DMEM was added into the upper chambers and the bottom chambers were filled with DMEM supplemented with $10 \%$ FBS. After $48 \mathrm{~h}$, the cells in the bottom chambers were stained using $0.1 \%$ crystal violet (Sigma-Aldrich; Merck KGaA, Darmstadt, Germany) for $10 \mathrm{~min}$ at room temperature. Cells were subsequently counted using an inverted light microscope at a magnification of $x 200$. The experiments were repeated a minimum of three times.

Statistical analysis. All data are presented as the mean \pm standard deviation. All statistical analysis was performed using SPSS 18.0 software (SPSS, Inc., Chicago, IL, USA) or GraphPad Prism 5.0 software (GraphPad Software, Inc., La Jolla, CA, USA). The data from two groups or multiple groups were compared using a Student's t-test or one-way analysis of variance followed by Tukey's post hoc test. The 
Table I. Association between miR-505 expression and the clinicopathological features of patients with breast cancer.

\begin{tabular}{|c|c|c|c|c|}
\hline \multirow[b]{2}{*}{ Feature } & \multirow[b]{2}{*}{$\begin{array}{l}\text { Total no. } \\
(n=128)\end{array}$} & \multicolumn{2}{|c|}{$\begin{array}{l}\text { miR-505 } \\
\text { expression }\end{array}$} & \multirow[b]{2}{*}{ P-value } \\
\hline & & $\begin{array}{c}\text { Low } \\
(n=66)\end{array}$ & $\begin{array}{c}\text { High } \\
(n=62)\end{array}$ & \\
\hline Age, years & & & & 0.798 \\
\hline$\leq 50$ & 44 & 22 & 22 & \\
\hline$>50$ & 84 & 44 & 40 & \\
\hline Tumor size, cm & & & & 0.160 \\
\hline$\leq 2$ & 62 & 28 & 34 & \\
\hline$>2$ & 66 & 38 & 28 & \\
\hline ER status & & & & 0.927 \\
\hline Negative & 80 & 41 & 39 & \\
\hline Positive & 48 & 25 & 23 & \\
\hline PR status & & & & 0.412 \\
\hline Negative & 81 & 44 & 37 & \\
\hline Positive & 47 & 22 & 25 & \\
\hline HER2 status & & & & 0.665 \\
\hline Negative & 87 & 46 & 41 & \\
\hline Positive & 41 & 20 & 21 & \\
\hline Distant metastasis & & & & 0.013 \\
\hline Negative & 90 & 40 & 50 & \\
\hline Positive & 38 & 26 & 12 & \\
\hline TNM stage & & & & 0.002 \\
\hline I-II & 60 & 22 & 38 & \\
\hline III-IV & 68 & 44 & 24 & \\
\hline
\end{tabular}

ER, estrogen receptor; PR, progesterone receptor; HER2, human epidermal growth factor receptor 2; miR-505, microRNA-505; TNM, Tumor-Node-Metastasis.

associations between miR-505 expression and clinicopathological parameters were analyzed using $\chi^{2}$ test. Survival analysis was performed using the Kaplan-Meier method and a log-rank test. The prognostic value of miR-505 was evaluated by Cox regression analysis. All the experiments were repeated at least three times. $\mathrm{P}<0.05$ was considered to indicate a statistically significant difference.

\section{Results}

Expression of miR-505 in BCa tissues and cells. As presented in Fig. 1, RT-qPCR revealed that the expression of miR-505 was significantly downregulated in $\mathrm{BCa}$ tissues compared with adjacent normal tissues $(\mathrm{P}<0.001)$. Similarly, a significantly lower expression level of miR-505 was identfied in the four BCa cell lines examined compared with the normal mammary cell line (all $\mathrm{P}<0.01)$.

Associations between miR-505 expression and the clinicopathological features of patients with $\mathrm{BC}$. Due to the dysreguled expression of miR-505 identified in $\mathrm{BCa}$, we hypothesized that
miR-505 may be involved in BCa development. Therefore, the associations between miR-505 expression level and the clinicopathological features of patients with $\mathrm{BCa}$ were assessed. The patients with $\mathrm{BCa}$ were divided into two groups based on the median expression value of miR-505 (1.124), which generated a low miR-505 expression group and a high miR-505 expression group. Notably, the expression of miR-505 was identifed to be associated with distant metastasis status $(\mathrm{P}=0.013)$ and TNM staging $(\mathrm{P}=0.002)$. However, no significant associations were revealed between miR-505 expression and other clinical parameters, including age, tumor size, ER status, PR status and HER2 status (all P>0.05; Table I).

Prognostic value of miR-505 in patients with BCa. Survival analysis was performed for the patients with different miR-505 expression levels. As presented in Fig. 2, Kaplan-Meier survival curves revealed that the overall survival time was significantly shorter for patients with low miR-505 expression compared with those with high miR-505 expression $(\mathrm{P}<0.001)$. Furthermore, miR-505 expression and other clinicopathological parameters were included in Cox regression analysis to identify prognostic factors for the overall survival of patients with $\mathrm{BCa}$. Univariate Cox analysis revealed that miR-505 expression [hazard ratio (HR), 3.972; 95\% confidence interval (CI), 2.044-7.720; $\mathrm{P}=0.012]$, distant metastasis (HR, 1.974; 95\% CI, 0.993-3.927; $\mathrm{P}=0.022$ ) and TNM stage (HR, 1.678; 95\% CI, 0.976-2.886; $\mathrm{P}=0.031$ ) were significantly associated with the overall survival rate of patients with BCa. Furthermore, multivariate analysis identified miR-505 expression $(\mathrm{HR}, 5.707$; 95\% CI, 2.798-11.638; $\mathrm{P}=0.001)$ and TNM stage (HR, 2.602; 95\% CI, 1.461-4.632; $\mathrm{P}=0.041$ ) as independent prognostic factors for the overall survival rate of patients with BCa (Table II).

Effects of miR-505 on the proliferation of BCa cells. In addition to assessing the expression of miR-505 in patients with $\mathrm{BCa}$ patients, the functional role of miR-505 in the progression of $\mathrm{BCa}$ was investigated using miR-505 mimic or miR-505 inhibitor to regulate miR-505 expression in BCa cells. MCF-7 and MDA-MB-231 cells were selected for transfection experiments as they exhibited low miR-505 expression levels. RT-qPCR confirmed that the expression of miR-505 was significantly higher in cells transfected with miR-505 mimic $(\mathrm{P}<0.001)$ and significantly lower in cells transfected with miR-505 inhibitor compared with the untreated cells $(\mathrm{P}<0.001$; Fig. $3 \mathrm{~A}$ and B). Subsequently, MTT assay demonstrated that an overexpression of miR-505 significantly inhibited the proliferation and knockdown of miR-505 significantly increased the proliferation of MCF-7 and MDA-MB-231 cells compared with the untreated cells (all $\mathrm{P}<0.05$; Fig. 3C and D).

Effects of miR-505 on BCa cell migration and invasion. Subsequently, Transwell and Matrigel assays were performed to assess the influence of miR-505 on $\mathrm{BCa}$ cell migration and invasion, respectively. As presented in Fig. 4A and B, compared with the untreated cells, the migration abilities of MCF-7 and MDA-MB-231 cells were significaly suppressed following an upregulation of miR-505 ( $\mathrm{P}<0.01$ for MCF-7, $\mathrm{P}<0.001$ for MDA-MB-231) and significantly increased 

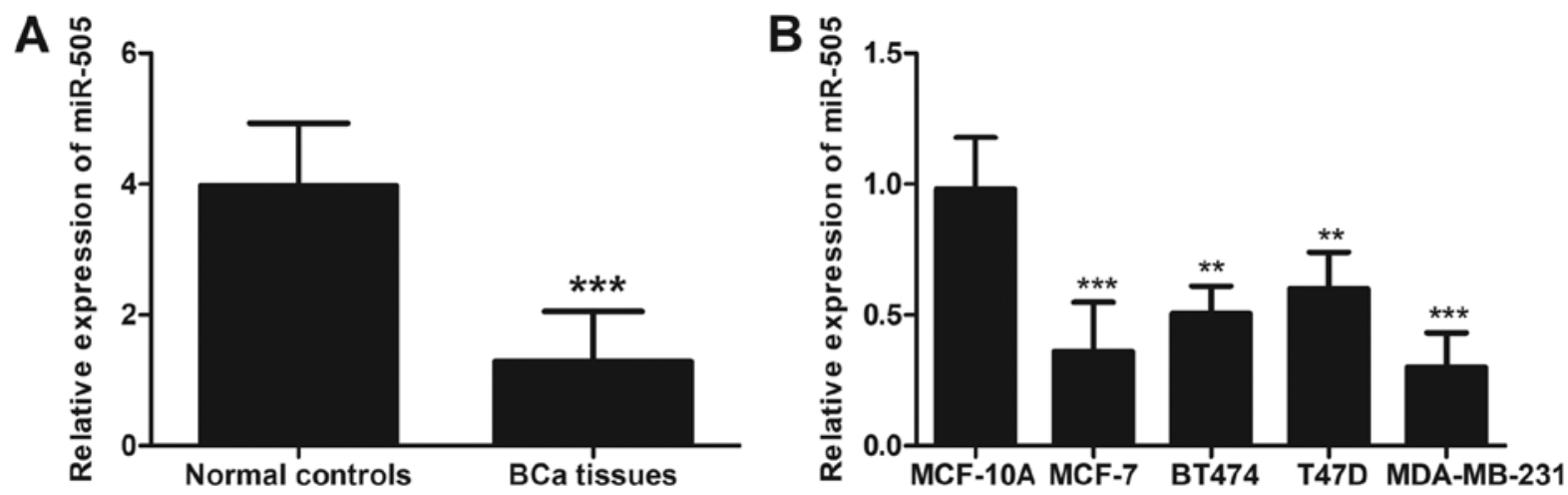

Figure 1. Expression patterns of miR-505 in BCa tissues and cell lines. (A) The expression of miR-505 was downregulated in BCa tissues (n=128) compared with the normal controls $(\mathrm{n}=128) .{ }^{* * *} \mathrm{P}<0.001$ vs. normal controls. (B) The expression level of miR-505 in four $\mathrm{BCa}$ cell lines was lower compared with that in normal cells. ${ }^{* *} \mathrm{P}<0.01,{ }^{* * *} \mathrm{P}<0.001$ vs. MCF-10A. BCa, breast cancer.

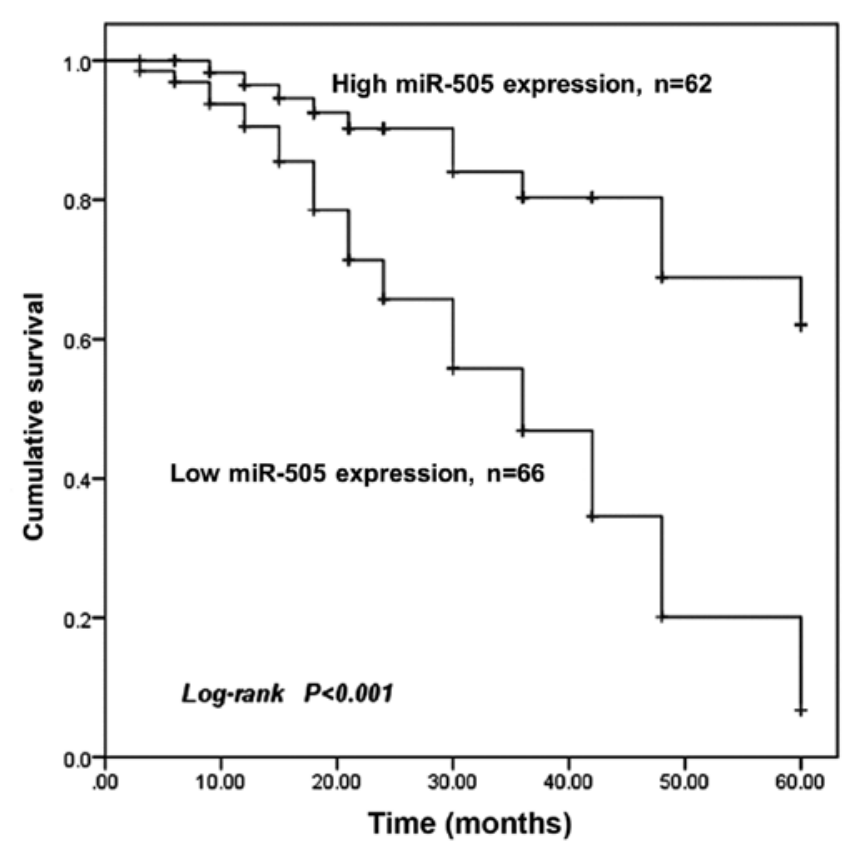

Figure 2. Kaplan-Meier survival curves for patients with BCa. The overall survival time was significantly shorter for patients with low miR-505 expression ( $\mathrm{n}=66)$ compared with patients with high miR-505 expression $(\mathrm{n}=62)$. $\mathrm{BCa}$, breast cancer; miR-505, microRNA-505.

following downregulation of miR-505 expression $(\mathrm{P}<0.01$ for both). As expected, an overexpression of miR-505 significantly reduced the number of invasive cells $(\mathrm{P}<0.001$ for MCF-7, $\mathrm{P}<0.01$ for MDA-MB-231) and a downregulation of miR-505 significantly increased the number of invasive MCF-7 and MDA-MB-231 cells compared with the untreated cells (all $\mathrm{P}<0.01$ for both; Fig. 4C and D).

\section{Discussion}

$\mathrm{BCa}$ is one the most frequent types of malignancy among females worldwide (25). Despite the development of various therapeutic strategies, including resection operation, chemotherapy and radiotherapy, the prognosis of patients diagnosed with $\mathrm{BCa}$ remains poor, which is predominantly due to the limited sensitivity and specificity of these treatment methods $(26,27)$. Therefore, this is an urgent requirement for the development of efficient treatment strategies for patients with BCa.

It has been reported that the initiation and development of $\mathrm{BCa}$ are complex processes that involve a wide range of genetic changes (28). Dysregulation of genes typically serves a pivotal role in the progression of $\mathrm{BCa}$ and exhibits significant potential for the improvement of BCa-targeted therapy (29). For example, increased expression of prolyl-4-hydroxylase $\alpha$ subunit 2 (P4HA2) in BCa can promote tumor cell proliferation and aggressive phenotypes, which indicates an oncogenic role of P4HA2 in tumor progression (30). Zhu et al (31) demonstrated that Sulfatase 2 (SULF2) could enhance cell proliferation, invasion, mobility and adhesion, and suppress apoptosis of BCa cells, which suggests that SULF2 may be a therapeutic target for $\mathrm{BCa}$ treatment. Over the past decades, a number of studies have reported important roles of miRNAs in numerous types of human cancer (32-34). In addition, miRNAs have been described as functional molecules during the progression of various types of malignancy, including $\mathrm{BCa}(35)$. Chai et al (36) indicated that BCa cell proliferation and cell cycle progression were promoted by miR-498, which was demonstrated to serve an oncogenic role in BCa progression by downregulating phosphatatse and tensin homolog expression. Furthermore, a downregulation of miR-202 expression has been observed in BCa tissues, and miR-202 was revealed to exert an inhibitory effect on cell proliferation, migration and invasion in BCa cells (37). These previous studies indicate that aberrant expression levels of miRNAs serve important roles in the tumor progression of $\mathrm{BCa}$.

In the present study, the expression level of miR-505 was identified to be significantly lower in BCa tissues compared with adjacent normal tissues. Similarly, the expression level of miR-505 was significantly lower in BCa cell lines compared with normal cells. Furthermore, the majority of patients with low miR-505 expression exhibited distant metastasis and presented with an advanced TNM stage. Therefore, it can be suggested that miR-505 may be involved in the development of $\mathrm{BCa}$. The present results were consistent with a previous study, which also identified a decreased expression of miR-505 in BCa tissues (22). Additionally, aberrant expression patterns of miR-505 have been detected in other types of human cancer. In hepatoma cells, the expression of miR-505 has been demonstrated to be downregulated and miR-505 was 
Table II. Cox regression analysis for miR-505 expression in patients with breast cancer.

\begin{tabular}{|c|c|c|c|c|c|c|}
\hline \multirow[b]{2}{*}{ Variable } & \multicolumn{3}{|c|}{ Univariate analysis } & \multicolumn{3}{|c|}{ Multivariate analysis } \\
\hline & HR & $95 \% \mathrm{CI}$ & P-value & $\mathrm{HR}$ & $95 \%$ CI & P-value \\
\hline miR-505 expression & 3.972 & $2.044-7.720$ & 0.012 & 5.707 & $2.798-11.638$ & 0.001 \\
\hline Age & 1.328 & $0.721-2.446$ & 0.364 & 1.032 & $0.544-1.958$ & 0.923 \\
\hline Tumor size & 1.398 & $0.807-2.420$ & 0.232 & 1.269 & $0.715-2.253$ & 0.416 \\
\hline ER status & 1.069 & $0.618-1.849$ & 0.811 & 1.023 & $0.566-1.895$ & 0.939 \\
\hline PR status & 1.036 & $0.587-1.829$ & 0.903 & 1.182 & $0.631-2.215$ & 0.601 \\
\hline HER2 status & 1.231 & $0.702-2.159$ & 0.469 & 1.232 & $0.669-2.268$ & 0.503 \\
\hline Distant metastasis & 1.974 & $0.993-3.927$ & 0.022 & 1.985 & $0.965-4.086$ & 0.062 \\
\hline TNM stage & 1.678 & $0.976-2.886$ & 0.031 & 2.602 & $1.461-4.632$ & 0.041 \\
\hline
\end{tabular}

ER, estrogen receptor; PR, progesterone receptor; HER2, human epidermal growth factor receptor 2; miR-505, microRNA-505; TNM, Tumor-Node-Metastasis; HR, hazard ratio; CI, confidence interval.

A

MCF-7

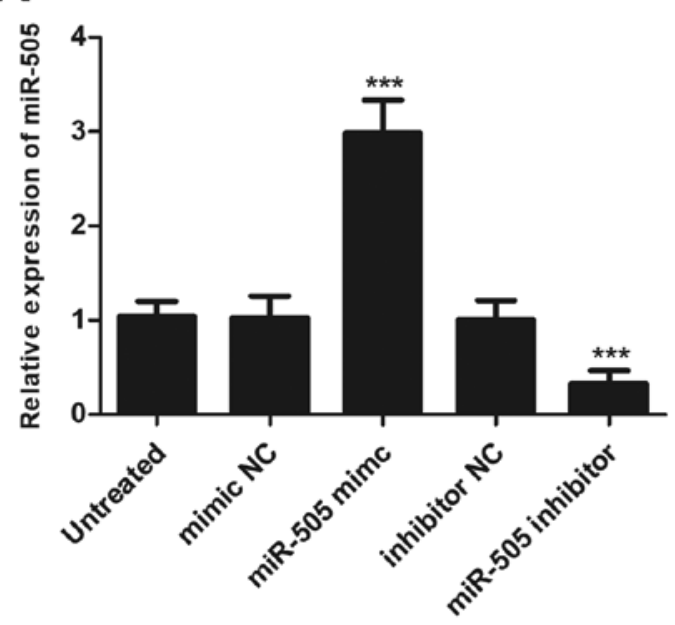

C

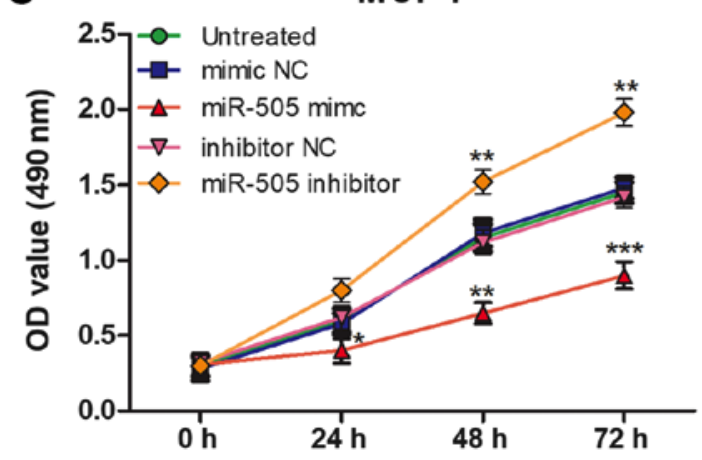

B

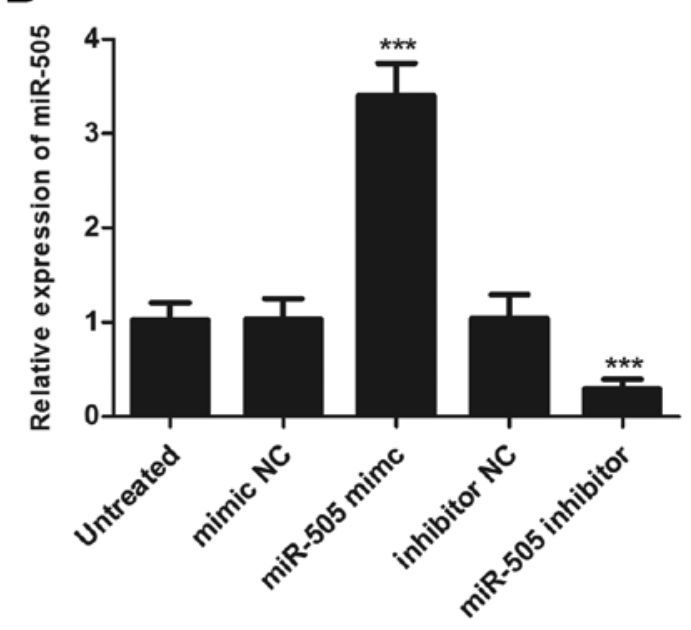

D

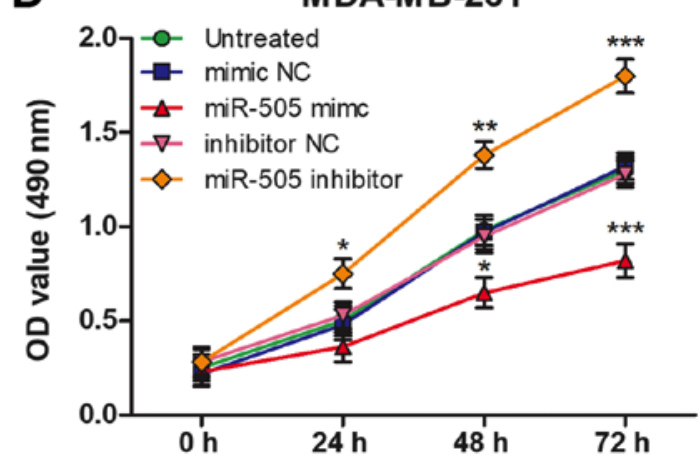

Figure 3. Effects of miR-505 on cell proliferation in the MCF-7 and MDA-MB-232 cell lines. The expression of miR-505 in (A) MCF-7 and (B) MDA-MB-232 cells was significantly higher following transfection with miR-505 mimic and significantly lower following transfection with miR-505 inhibitor compared with untreated cells ${ }^{* * * *} \mathrm{P}<0.001$. Proliferation of (C) MCF-7 and (D) MDA-MB-231 cells was significantly inhibited following transfection with miR-505 mimic and significantly enhanced following overexpression of miR-505. All experiments were repeated three times. ${ }^{*} \mathrm{P}<0.05,{ }^{* * *} \mathrm{P}<0.01,{ }^{* * * *} \mathrm{P}<0.001 \mathrm{vs}$. untreated. miR-505, microRNA-505; NC, negative control; OD, optical density.

identified to promote cell proliferation and invasion by regulating high-mobility group box 1 (20). Similarly, downregulated miR-505 expression has been identified in endometrial cancer tissues and was involved in tumor progression, with a tumor suppressor role in this disease (21). Therefore, we hypothesize that miR-505 may be a tumor suppressor in BCa.

Given the dysregulated miR-505 expression in BCa tissues, the current study evaluated the prognostic value of miR-505 in 

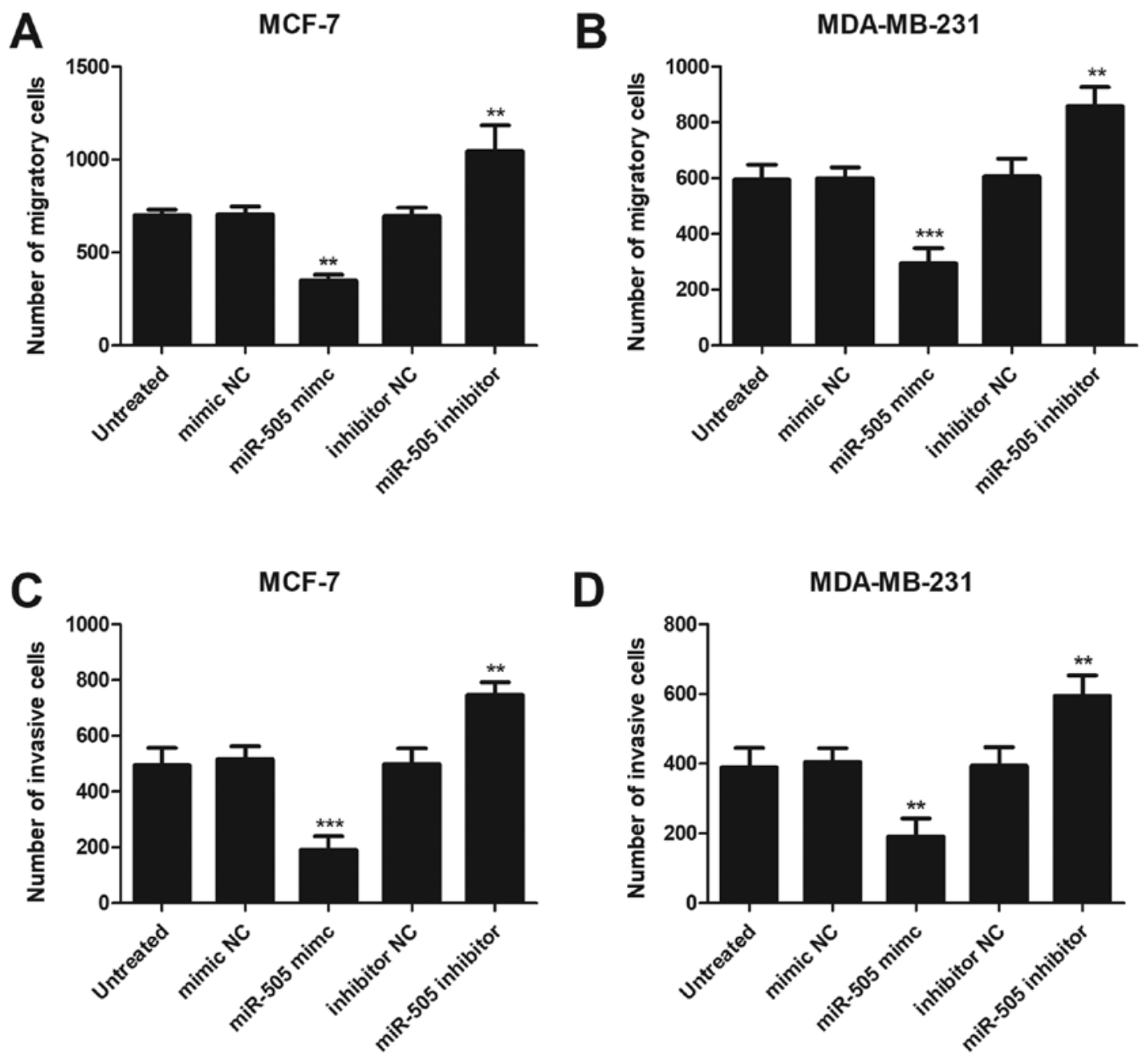

Figure 4. Effects of miR-505 on the migration and invasion of MCF-7 and MDA-MB-232 cells. An upregulation of miR-505 suppressed, whereas a downregulation of miR-505 promoted the migration of (A) MCF-7 and (B) MDA-MB-232 cells. Cell invasion examined by Transwell assay was inhibited by miR-505 overexpression and enhanced by miR-505 downregulation in (C) MCF-7 and (D) MDA-MB-231 cell lines. All experiments were repeated three times. ${ }^{* *} \mathrm{P}<0.01$ and ${ }^{* * *} \mathrm{P}<0.001$ vs. untreated. miR-505, microRNA-505; NC, negative control.

BCa. The clinical significance of miRNAs has received increasing attention due to their high diagnostic and prognostic potential in different types of human cancer $(38,39)$. Certain miRNAs have been identified as diagnostic or prognostic biomarkers in $\mathrm{BCa}$, including miR-204 (40) and miR-301a (41). Ma et al (19) reported that downregulated miR-505 expression predicts poor prognosis in cervical cancer. However, to the best of our knowledge, the clinical significance of miR-505 has infrequently been reported in $\mathrm{BCa}$. In the present study, the Kaplan-Meier method was used to plot survival curves for patients with $\mathrm{BCa}$, which demonstrated that patients with low miR-505 expression exhibited a shorter overall survival time compared with those with high miR-505 expression. Additionally, univariate Cox analysis demonstrated that miR-505 expression, distant metastasis and TNM stage were associated with overall survival of patients with BCa. Multivariate Cox analysis further validated that miR-505 expression and TNM stage were independent prognostic factors for patients with $\mathrm{BCa}$. Although distant metastasis is considered an aggressive behavior in $\mathrm{BCa}$ and may predict a poor prognosis, an independent association between distant metastasis and overall survival was not identified during multivariate analysis. This result may be due to the effects of other parameters in the equations of multivariate analysis or due to the cohort size used in the present study, which may be a limitation.
To further investigate the biological function of miR-505 in BCa progression, the effects of miR-505 on BCa cell proliferation, migration and invasion were assessed. The expression of miR-505 was regulated by cell transfection with miR-505 mimic or miR-505 inhibitor. According to MTT and Transwell assays, it was identified that upregulation of miR-505 could inhibit the proliferation, migration and invasion of $\mathrm{BCa}$ cells, whereas a downregulation of miR-505 could promote the proliferation, migration and invasion of BCa cells. Therefore, it can be suggested that miR-505 serves an inhibitory role in BCa progression. In endometrial cancer, miR-505 also acts as a tumor suppressor and suppresses tumor cell biological behaviors by targeting tumor growth factor- $\alpha$ (21). In addition, antitumor effects of miR-505 in cervical carcinoma can be achieved by downregulating the expression of Frizzled-4 (19). However, to the best of our knowledge, the molecular mechanisms underlying the role of miR-505 in BCa remain unknown and require further investigation.

In conclusion, the present results demonstrated that miR-505 expression is decreased in $\mathrm{BCa}$ and serves as an independent prognostic biomarker. Overexpression of miR-505 was demonstrated to suppress $\mathrm{BCa}$ cell proliferation, migration and invasion, which indicates miR-505 may potentially be used to improve targeted therapy for patients with BCa. 


\section{Acknowledgements}

Not applicable.

\section{Funding}

No funding was received.

\section{Availability of data and materials}

The analyzed datasets generated during the study are available from the corresponding author on reasonable request.

\section{Authors' contributions}

JW and HL designed the study, performed the clinical research, analyzed the data and wrote the manuscript. ML performed the cell experiments. All authors read and approved the final manuscript.

\section{Ethics approval and patient consent}

Each patient provided written informed consent and their personal information was anonymized. The experimental procedures of the present study were approved by the Ethics Committee of Yidu Central Hospital of Weifang (Weifang, China).

\section{Patient consent for publication}

Not applicable.

\section{Competing interests}

The authors declare that they have no competing interests.

\section{References}

1. Torre LA, Bray F, Siegel RL, Ferlay J, Lortet-Tieulent J and Jemal A: Globalcancer statistics, 2012. CA Cancer J Clin 65 87-108, 2015

2. Brenton JD, Carey LA, Ahmed AA and Caldas C: Molecular classification and molecular forecasting of breast cancer: Ready for clinical application? J Clin Oncol 23: 7350-7360, 2005.

3. Bombonati A and Sgroi DC: The molecular pathology of breast cancer progression. J Pathol 223: 307-317, 2011.

4. Reis-Filho JS and Lakhani SR: The diagnosis and management of pre-invasive breast disease: Genetic alterations in pre-invasive lesions. Breast Cancer Res 5: 313-319, 2003.

5. Dai K, Qin F, Zhang H, Liu X, Guo C, Zhang M, Gu F, Fu L and Ma Y: Low expression of BMPRIB indicates poor prognosis of breast cancer and is insensitive to taxane-anthracycline chemotherapy. Oncotarget 7: 4770-4784, 2016.

6. Schmitz KH, DiSipio T, Gordon LG and Hayes SC: Adverse breast cancer treatment effects: The economic case for making rehabilitative programs standard of care. Support Care Cancer 23: 1807-1817, 2015.

7. Turchinovich A, Weiz L and Burwinkel B: Extracellular miRNAs: The mystery of their origin and function. Trends Biochem Sci 37: 460-465, 2012.

8. Pillai RS, Bhattacharyya SN, Artus CG, Zoller T, Cougot N, Basyuk E, Bertrand E and Filipowicz W: Inhibition of translational initiation by Let-7 MicroRNA in human cells. Science 309: $1573-1576,2005$

9. Xiang J, Wu Y, Li DS, Wang ZY, Shen Q, Sun TQ, Guan Q and Wang YJ: MiR-584 suppresses invasion and cell migration of thyroid carcinoma by regulating the target oncogene ROCK1. Oncol Res Treat 38: 436-440, 2015.
10. Lu Y, Hu J, Sun W, Li S, Deng S and Li M: MiR-29c inhibits cell growth, invasion, and migration of pancreatic cancer by targeting ITGB1. Onco Targets Ther 9: 99-109, 2016.

11. Bai J, Zhang Z, Li X and Liu H: MicroRNA-365 inhibits growth, invasion and metastasis of malignant melanoma by targeting NRP1 expression. Cancer Biomark 15: 599-608, 2015.

12. Zhou C, Lu Y and Li X: MiR-339-3p inhibits proliferation and metastasis of colorectal cancer. Oncol Lett 10: 2842-2848, 2015.

13. Dan B, Luo J, Li K and Chen S: Prognostic value of miR-375 for survival outcomes in various cancers: A systematic review and meta-analysis. Oncol Res Treat 41: 47-50, 2018.

14. Lin F, Yao L, Xiao J, Liu D and Ni Z: MiR-206 functions as a tumor suppressor and directly targets K-Ras in human oral squamous cell carcinoma. Onco Targets Ther 7: 1583-1591, 2014.

15. Zheng K, Liu W, Liu Y, Jiang C and Qian Q: MicroRNA-133a suppresses colorectal cancer cell invasion by targeting Fascin1. Oncol Lett 9: 869-874, 2015.

16. Yang H, Yu J, Wang L, Ding D, Zhang L, Chu C, Chen Q, Xu Z, Zou Q and Liu X: miR-320a is an independent prognostic biomarker for invasive breast cancer. Oncol Lett 8: 1043-1050, 2014.

17. Deng Y and Chen Y: Increased expression of miR-29a and its prognostic significance in patients with cholangiocarcinoma. Oncol Res Treat 40: 128-132, 2017.

18. Liu YJ, Li W, Chang F, Liu JN, Lin JX and Chen DX: MicroRNA-505 is downregulated in human osteosarcoma and regulates cell proliferation, migration and invasion. Oncol Rep 39: 491-500, 2018.

19. Ma C, Xu B, Husaiyin S, Wang L, Wusainahong K, Ma J, Zhu K and Niyazi M: MicroRNA-505 predicts prognosis and acts as tumor inhibitor in cervical carcinoma with inverse association with FZD4. Biomed Pharmacother 92: 586-594, 2017.

20. Lu L, Qiu C, Li D, Bai G, Liang J and Yang Q: MicroRNA-505 suppresses proliferation and invasion in hepatoma cells by directly targeting high-mobility group box 1. Life Sci 157: 12-18, 2016.

21. Chen S, Sun KX, Liu BL, Zong ZH and Zhao Y: MicroRNA-505 functions as a tumor suppressor in endometrial cancer by targeting TGF-alpha. Mol Cancer 15: 11, 2016.

22. Matamala N, Vargas MT, Gonzalez-Campora R, Minambres R, Arias JI, Menendez P, Andres-Leon E, Gomez-Lopez G, Yanowsky K, Calvete-Candenas J, et al: Tumor microRNA expression profiling identifies circulating microRNAs for early breast cancer detection. Clin Chem 61: 1098-1106, 2015.

23. Singletary SE, Allred C, Ashley P, Bassett LW, Berry D, Bland KI, Borgen PI, Clark GM, Edge SB, Hayes DF, et al: Staging system for breast cancer: Revisions for the 6th edition of the AJCC Cancer Staging Manual. Surg Clin North Am 83: 803-819, 2003.

24. Livak KJ and Schmittgen TD: Analysis of relative gene expression data using real-time quantitative PCR and the 2(-Delta Delta $\mathrm{C}(\mathrm{T})$ ) method. Methods 25: 402-408, 2001

25. Akram M, Iqbal M, Daniyal $M$ and Khan AU: Awareness and current knowledge of breast cancer. Biol Res 50: 33, 2017.

26. Shi M and Guo N: MicroRNA expression and its implications for the diagnosis and therapeutic strategies of breast cancer. Cancer Treat Rev 35: 328-334, 2009.

27. Blank PR, Schwenkglenks M, Moch H and Szucs TD: Human epidermal growth factor receptor 2 expression in early breast cancer patients: A swiss cost-effectiveness analysis of different predictive assay strategies. Breast Cancer Res Treat 124: 497-507, 2010.

28. Byler S, Goldgar S, Heerboth S, Leary M, Housman G, Moulton K and Sarkar S: Genetic and epigenetic aspects of breast cancer progression and therapy. Anticancer Res 34: 1071-1077, 2014.

29. Lei F, Zhang L, Li X, Lin X, Wu S, Li F and Liu J: Overexpression of prostate tumor overexpressed 1 correlates with tumor progression and predicts poor prognosis in breast cancer. BMC Cancer 14: 457, 2014.

30. Xiong G, Deng L, Zhu J, Rychahou PG and Xu R: Prolyl-4-hydroxylase alpha subunit 2 promotes breast cancer progression and metastasis by regulating collagen deposition. BMC Cancer 14: 1, 2014

31. Zhu C, He L, Zhou X, Nie X and Gu Y: Sulfatase 2 promotes breast cancer progression through regulating some tumor-related factors. Oncol Rep 35: 1318-1328, 2016.

32. Dragomir M, Mafra ACP, Dias SMG, Vasilescu C and Calin GA: Using microRNA networks to understand cancer. Int J Mol Sci 19: E1871, 2018.

33. Huang LL, Huang LW, Wang L, Tong BD, Wei Q and Ding XS: Potential role of miR-139-5p in cancer diagnosis, prognosis and therapy. Oncol Lett 14: 1215-1222, 2017. 
34. Long JP, Dong LF, Chen FF and Fan YF: miR-146a-5p targets interleukin-1 receptor-associated kinase 1 to inhibit the growth, migration, and invasion of breast cancer cells. Oncol Lett 17: 1573-1580, 2019.

35. Sun EH, Zhou Q, Liu KS, Wei W, Wang CM, Liu XF, Lu C and Ma DY: Screening miRNAs related to different subtypes of breast cancer with miRNAs microarray. Eur Rev Med Pharmacol Sci 18: 2783-2788, 2014.

36. Chai C, Wu H, Wang B, Eisenstat DD and Leng RP: MicroRNA-498 promotes proliferation and migration by targeting the tumor suppressor PTEN in breast cancer cells. Carcinogenesis 39: 1185-1196, 2018.

37. Gao S, Cao C, Dai Q, Chen J and Tu J: miR-202 acts as a potential tumor suppressor in breast cancer. Oncol Lett 16: 1155-1162, 2018.
38. Lu X and Lu J: The significance of detection of serum miR-423-5p and miR-484 for diagnosis of colorectal cancer. Clin Lab 61: 187-190, 2015.

39. Cong J, Liu R, Wang X, Wang J, Wang H and Hou J: Low miR-498 expression levels are associated with poor prognosis in ovarian cancer. Eur Rev Med Pharmacol Sci 19: 4762-4765, 2015.

40. Li W, Jin X, Zhang Q, Zhang G, Deng X and Ma L: Decreased expression of miR-204 is associated with poor prognosis in patients with breast cancer. Int J Clin Exp Pathol 7: 3287-3292, 2014.

41. Yu H, Li H, Qian H, Jiao X, Zhu X, Jiang X, Dai G and Huang J: Upregulation of miR-301a correlates with poor prognosis in triple-negative breast cancer. Med Oncol 31: 283, 2014. 